\title{
US Bioethics Commission meets, outlines agenda
}

Meeting for the first time in October, members of the US National Bioethics Advisory Commission (NBAC, Washington, DC) established a spirit of cordial informality and gingerly avoided becoming bogged down by peculiar technicalities of federal conflict-ofinterest rules. They also took modest steps to shape an agenda to consider over the next few years of regular meetings. The annual operating budget for the commission will rise from the current $\$ 500,000$ to the eventual target of \$1-2 million, according to chairman Harold Shapiro, who is president of Princeton University (Princeton, NJ).

NBAC members appear to be slating several issues of importance to the biotechnology industry for near-term consideration, including the use of human subjects in biomedical research, genetic privacy and related tissue sample usage issues, and possibly gene patenting.

No single issue drew more attention than concerns with the overall operation of institutional review boards (IRBs) - the sprawling, locally operating but federally sanctioned, system for reviewing biomedical research protocols and protecting the rights of human subjects. The US National Institutes of Health (NIH, Bethesda, MD) oversees this system, requiring institutions that receive federal funds for research to abide by certain minimal standards for establishing and maintaining IRBs. Although a national interagency group broadly reviews IRB performance and poli- cies, in practical terms the Office for Protection from Research Risks (OPRR) within $\mathrm{NIH}$ takes the lead in dealing with IRBs.

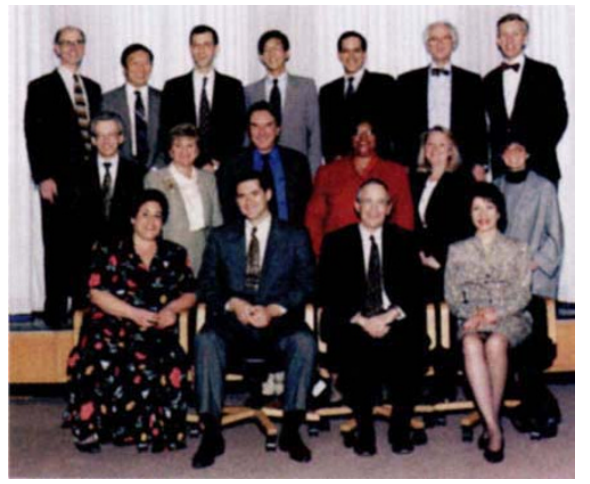

Members of US National Bioethics Advisory Commission: (From left to right) back row, T.H. Murray, L.H. Miike, E.J. Emanuel, B. Lo, S.H. Holtzman, E.J. Cassell, A.M. Capron; second row, J.Childress, B.O. Kramer, D.R. Cox, R.G. Dumas, L.M. Flynn, P. Backlar; front row, R.H. Charo, A. Brito, H.T. Shapiro, D. Scott-Jones.

Despite a good performance record, there are shortcomings to the IRB system that reflect the way it was established and affect the way it performs. "In 1996, we don't have the tools to protect all human subjects," points out OPRR director Gary Ellis. There is no federal statute applicable to such research, meaning current rules do not apply universally. Moreover, the IRB system is far from uniform-a factor that sometimes proves frustrating or worse for investigators conducting multisite clinical trials.

Francis Collins, director of the NIH National Center for Human Genome Research, has urged NBAC members to put genetic privacy issues high on their agenda. As data associating specific diseases with molecular-level genetics continues to accumulate, he says, the potential for abuses by insurers and employers also grows. "One of the most troubling issues is healthy persons with genetic information that may be predictive of a disease," he says. Another narrower, but more immediate, issue revolves around the future use of DNA-containing tissue specimens now held by pathologists; unauthorized testing of such samples also could lead to abuses. Hence, he says, strong NBAC recommendations in these areas would be welcome.

Representatives from the biotechnology industry agree that genetic testing information should be protected from abuse. However, in calling for a "flexible regulatory framework," Suzanne Tomlinson from the Biotechnology Industry Organization (BIO, Washington, DC) recommends that Congress not single out genetic testing technology but, instead, "pass a comprehensive medical privacy bill that includes protections for genetic privacy."

Jeffrey L. Fox especially for children, and are a staple crop in developing countries. The BTI has recently received a three-year foundation grant from the Rockefeller Foundation (New York) to set up links with researchers at the Centro de Investigacion $y$ de Estudios Avanzados del IPN (CINESTAV, Mexico City) to develop the banana transformation system and maximize LT-B expression levels in transformed bananas.

Other researchers see a fundamental disadvantage with the banana system: They regenerate only slowly. It could be two years at least, for instance, before BTI can evaluate the antigen levels in its banana transformants. Consequently, Koprowski is using transgenic tomatoes and alfalfa-plants in which expression levels can readily be assessed within months-for his rabies and HIV vaccines. Faster still is another of the Jefferson group's approaches: the use of plant viral vectors that express the antigen gene to infect plants. Using this method,

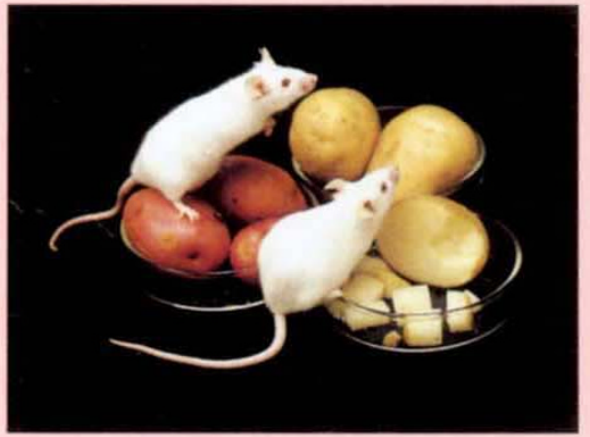

The BTI potato vaccine, which stimulates the production of antientertoxin IgG and IgA in mice.

researchers can optimize antigen production level in days.

The plant virus method is also being developed by Axis Genetics (Cambridge, UK). Axis' most advanced project involves an animal vaccine: Injecting mink with extracts of plants infected with a cowpea mosaic virus that expresses a mink enteritis antigen gene protects the animal against subsequent virus challenge, according to CEO Iain Cubitt. The next phase for Axis will be to demonstrate the efficacy of vaccines administered orally as plant material, a milestone Cubitt expects to pass "within the next year." Neither the enteritis vaccine nor a parvovirus vaccine that Axis is developing as part of an European Union-funded program have yet been administered through the oral route.

Despite these more rapid methods, the BTI trial remains of considerable significance as a proof of principle. "Everyone is waiting for us to actually prove that this works," says Charles Arntzen. The first trials next April, however, will not resolve this completely. Although the volunteers will be tested for altered immunological status, they will not be challenged with the E. coli toxin.

Emma Johnson 